\title{
Randomized Crossover Study of the Long-Term Effects of Pilsicainide and Cibenzoline in Preventing Recurrence of Symptomatic Paroxysmal Atrial Fibrillation
}

\author{
Influence of the Duration of Arrhythmia \\ Before Therapy
}

\author{
Takashi Komatsu, MD; Yoshihiro Sato, MD; Hideaki Tachibana, MD; \\ Motoyuki Nakamura, MD; Daisuke Horiuchi, MD*; Ken Okumura, MD*
}

\begin{abstract}
Background There is little information on the selection of antiarrhythmic agents for long-term prevention of paroxysmal atrial fibrillation (PAF). In the present study the preventive effects of pilsicainide (Pil) and cibenzoline (Cib) were compared in patients with PAF that was defibrillated at $<48 \mathrm{~h}$ or $\geq 48 \mathrm{~h}$ after onset.

Methods and Results A total of 60 patients ( 45 men, 15 women, mean age $66 \pm 10$ years) were divided into 2 groups: Group I consisted of 22 patients in whom atrial fibrillation (AF) lasted for $<48 \mathrm{~h}$ before cardioversion and Group II consisted of 38 patients in whom AF lasted for $\geq 48 \mathrm{~h}$. A randomized, crossover protocol of treatment with Pil ( $150 \mathrm{mg} / \mathrm{day})$ and Cib ( $300 \mathrm{mg} / \mathrm{day})$ was used. Mean follow-up was $35 \pm 18$ months. In Group I, the mean duration of maintenance of sinus rhythm was $12.3 \pm 2.9$ months in patients treated with Pil, compared with $12.9 \pm 2.5$ months in those givem $\mathrm{Cib}$ ( $\mathrm{p}=\mathrm{NS}$ between 2 groups). Actuarial event-free rates at 1, 3, 6, 12 months were $82 \%, 68 \%, 59 \%$ and $41 \%$, respectively, in patients treated with Pil, and $91 \%, 77 \%, 68 \%$ and $50 \%$, respectively, in those givenh $\mathrm{Cib}$ ( $\mathrm{p}=\mathrm{NS}$ between 2 groups). In Group II, the mean duration of maintenance of sinus rhythm was $1.6 \pm 0.5$ months in patients treated with Pil, compared with $5.9 \pm 1.7$ months in those given Cib $(\mathrm{p}<0.01)$. Actuarial event-free rates at 1, 3, 6, 12 months were $45 \%, 18 \%, 8 \%$ and $3 \%$, respectively, in patients treated with Pil, and 63\%, 45\%, 29\% and 16\%, respectively, in those given Cib ( $<<0.05$, at 12 months).

Conclusions Prolonged tachycardia $(\geq 48 \mathrm{~h})$ in patients with PAF seems to cause electrical remodeling. Cib, a multichannel blocker, is considered to be more effective in preventing the recurrence of PAF in the electrically remodeled atria than Pil, a pure sodium-channel blocker. (Circ J 2006; 70: 667-672)
\end{abstract}

Key Words: Antiarrhythmic therapy; Atrial fibrillation; Electrical remodeling; Prevention

$\Delta^{\mathrm{t}}$ trial fibrillation (AF) is a common arrhythmia in the elderly population because the prevalence of the arrhythmia increases with age. AF not only impairs quality of life but also causes serious complications such as systemic embolism and hemodynamic dysfunction. AF seriously affects the prognosis of patients, especially of those with impaired left ventricular (LV) function and old age , $^{1,2}$ In the aging society of Japan, AF has been recognized as one of the diseases requiring long-term treatment and follow-up? The clinical course of AF is generally believed to be initiated in the paroxysmal form, gradually perpetuated, and finally become persistent. In an experimental animal model, while the duration of the paroxysmal form of AF (PAF) was sustained, the arrhythmia can be easily provoked by any stimuli and it becomes hard to restore normal sinus rhythm (SR). To explain this time-based

(Received January 25, 2006; revised manuscript received March 16, 2006; accepted March 28, 2006)

Second Department of Internal Medicine, Iwate Medical University School of Medicine, Morioka, *Second Department of Internal Medicine, Hirosaki University School of Medicine, Hirosaki, Japan.

Mailing address: Takashi Komatsu, MD, The Second Department of Internal Medicine, Iwate Medical University School of Medicine, 19-1 Uchimaru, Morioka 021-8505, Japan. E-mail: takashi-komatu@ pref.iwate.jp mechanism, the concept known as "remodeling phenomenon" was introduced5 After long duration of AF, various ion channels in the atrial muscle are gradually up-regulated or down-regulated. It is considered, therefore, that the preventive effect of treatment with antiarrhythmic agents varies with the progression of electrical remodeling. However, it is unclear whether the duration of tachycardia affects the long-term preventive effect of different types of antiarrhythmic agents for patients with recurrent PAF.

In this study, we designed a randomized crossover study to compare the preventive effect of 2 ion channel inhibitory antiarrhythmic agents, pilsicainide (Pil) and cibenzoline (Cib).

\section{Methods}

\section{Study Patients}

This study was performed from April, 1997 to August, 2002 , and the mean observation period was $35 \pm 18$ months for all patients. Sixty patients ( 45 males, 15 females; mean age, 66 \pm 10 years, range 32-79) with symptomatic and recurrent PAF, who were followed up once or twice each month at the outpatient clinic of Iwate Prefectural Iwai Hospital to receive antiarrhythmic therapy for their symptoms such as palpitation that were impairing quality of life. 
Table 1 Clinical Profiles of Group I and Group II Patients

\begin{tabular}{lccc}
\hline \hline & $\begin{array}{c}\text { Group } 1 \\
(n=22)\end{array}$ & $\begin{array}{c}\text { Group } 2 \\
(n=38)\end{array}$ & p value \\
\hline Age (years) & $65 \pm 11$ & $66 \pm 9$ & $N S$ \\
M/F & $15: 7$ & $30: 8$ & $N S$ \\
Bodyweight $(k g)$ & $60 \pm 8$ & $61 \pm 9$ & $N S$ \\
Smoking & $6(27 \%)$ & $14(37 \%)$ & $N S$ \\
Hypertension & $7(32 \%)$ & $20(53 \%)$ & $N S$ \\
Diabetes mellitus & $3(14 \%)$ & $9(24 \%)$ & $N S$ \\
Hyperlipidemia & $3(14 \%)$ & $1(3 \%)$ & $N S$ \\
Hyperuricemia & $0(0 \%)$ & $0(0 \%)$ & $N S$ \\
Alcohol & $10(46 \%)$ & $21(55 \%)$ & $N S$ \\
Duration (months) & $22 \pm 41$ & $25 \pm 36$ & $N S$ \\
Underlying heart disease & $5(23 \%)$ & $9(24 \%)$ & $N S$ \\
Underlying pulmonary disease & $2(9 \%)$ & $2(5 \%)$ & $N S$ \\
ACE inhibitor & $4(18 \%)$ & $7(18 \%)$ & $N S$ \\
LVDd (mm) & $45 \pm 6$ & $46 \pm 5$ & $N S$ \\
LAD (mm) & $32 \pm 6$ & $37 \pm 6$ & $<0.01$ \\
LVEF (\%) & $70 \pm 8$ & $68 \pm 11$ & NS \\
HANP at SR (pg/ml) & $41 \pm 29$ & $50 \pm 42$ & NS \\
Time of onset & & & \\
Diurnal: $n o c t u r n a l: m i x e d$ & $2: 6: 14$ & $5: 3: 30$ & NS \\
\hline Continus & & &
\end{tabular}

Continuous values are mean $\pm S D$. Values in parentheses are \%.

$A C E$, angiotensin-converting enzyme; LVDd, left ventricular end-diastolic dimension; $L A D$, left atrial dimension; $L V E F$, left ventricular ejection fraction; HANP, human atrial natriuretic polypeptide; SR, sinus rhythm.

The presence of AF which corresponded with subjective symptoms was confirmed on 12-lead or ambulatory 24-h ECG recording in all patients, and the clinical course had been observed for $>12$ months for maintaining SR.

In all patients, we performed noninvasive tests such as chest X-ray examination, ECG recording, exercise ECG testing, and echocardiography to clarify underlying heart disease before the initiation of antiarrhythmic therapy. When it was considered necessary by the treating physician, ambulatory 24-h ECG recording was repeated and cardiac catheterization was also carried out. If there were abnormal findings with regard to pulmonary disease, then pulmonary function tests and chest computed tomography (CT) scanning were performed. In this study, the plasma atrial natriuretic polypeptide (ANP) level at SR was measured in blood taken from a vein in the upper extremity while supine at rest.

Onset of AF in each group was described as follows based on symptom onset: (1) diurnal type: AF occurring between $07.00 \mathrm{~h}$ and $17.00 \mathrm{~h}$; (2) nocturnal type: AF occurring between $17.00 \mathrm{~h}$ and $07.00 \mathrm{~h}$ the next morning; and (3) mixed type: AF occurring within both time intervals. Patients for whom the development of AF was observed on the ECG recording in addition to ambulatory 24-h ECG and for whom AF had already been identified at consultation were assigned to one of the groups. All episodes in patients with AF were confirmed by the ECG recording or ambulatory 24-h ECG. For patients who already had a documented episode of AF on ECG recording during hospital visit, we defined the time of occurrence as the initiation of the same symptoms with which AF had occurred.

Patients with congestive heart failure, serious bradycardia $<40$ beats/min, severe intraventricular conduction disturbance, liver or renal dysfunction with abnormal laboratory test values, LV ejection fraction (LVEF) $<40 \%$ determined by echocardiography, concomitantly receiving digitalis, $\beta$ or calcium-channel blocker or other serious complications were excluded.

\section{Protocol of Cardioversion}

Pharmacological or electrical cardioversion under anesthesia using intravenous thiopental $(2-5 \mathrm{mg} / \mathrm{kg})$ was immediately performed for patients in whom duration of AF was $<48 \mathrm{~h}$ ? For patients in whom the duration of AF was $\geq 48 \mathrm{~h}$, pharmacological or electrical cardioversion was performed with additional intravenous administration of heparin $(100 \mathrm{IU} / \mathrm{kg}$ ) following confirmation of the absence of blood clots or spontaneous echo contrast in the left atrium on transesophageal echocardiography? Anticoagulant treatment using warfarin was then initiated immediately after cardioversion and therapy was continued for $\geq 4$ weeks for cases in which AF occurred before the American Heart Association (AHA) guidelines ${ }^{7}$ were recommended. In cases of AF occurring after the recommendations of the AHA guideline, anticoagulant treatment using warfarin was administered for 3 weeks and then electrical cardioversion was performed. Warfarin was again administered for 4 weeks after obtaining cardioversion. The dose of warfarin treatment was set so as to obtain international normalized ratio between 1.6 and 2.6.

\section{Protocol of Antiarrhythmic Agent Therapy}

Patients with PAF that had been confirmed on ECG and in whom the ECG findings were clearly consistent with the subjective symptoms were registered in this study. After SR was restored by spontaneous arrest or cardioversion, an anti-arrhythmic agent, either Pil $(150 \mathrm{mg} /$ day) or Cib $(300 \mathrm{mg} /$ day $)$, was randomly selected using the envelope method. The selected agent was regarded as the first-line agent and oral administration was begun. If recurrence of AF occurred on ECG during follow-up, another agent (the second-line agent) was orally administered from the day when spontaneous arrest was observed on follow-up monitoring. Conversely, if spontaneous arrest did not occur, another agent was orally administered as the second-line agent from the same day following performance of electrical cardioversion. The development of recurrence was determined through subjective symptoms in addition to ECG findings at 2 weeks after initial administration of the anti-arrhythmic agent or 2 weeks after switching to the second-line agent. In all patients ambulatory 24-h ECG was performed as necessary at 2 or 4 weeks after starting oral administration of the first-line or second-line agent at the time of re-consultation and was repeated at a 3-month interval or when it was considered to be necessary by the physician.

The recurrence of AF was defined as the initial episode of AF on ECG recording after the administration of the firstline or second-line agent. If recurrence of AF was observed after the administration of the second-line agent, another class I antiarrhythmic agent that had not been used before or amiodarone was administered at the discretion of the treating physician. Verbal or written informed consent regarding the therapeutic strategy in this study was given by all patients

\section{Definitions and Statistical Analysis}

PAF was defined as AF terminating spontaneously within 7 days of onset. Duration of AF was the period from the initial episode of PAF to the time of the initiation of antiarrhythmic therapy. Hypertension was defined as a casual systolic blood pressure greater than $160 \mathrm{mmHg}$ at systole or $95 \mathrm{mmHg}$ at diastole? Ischemic stroke was diagnosed by the typical symptoms and the development of a new low- 
A

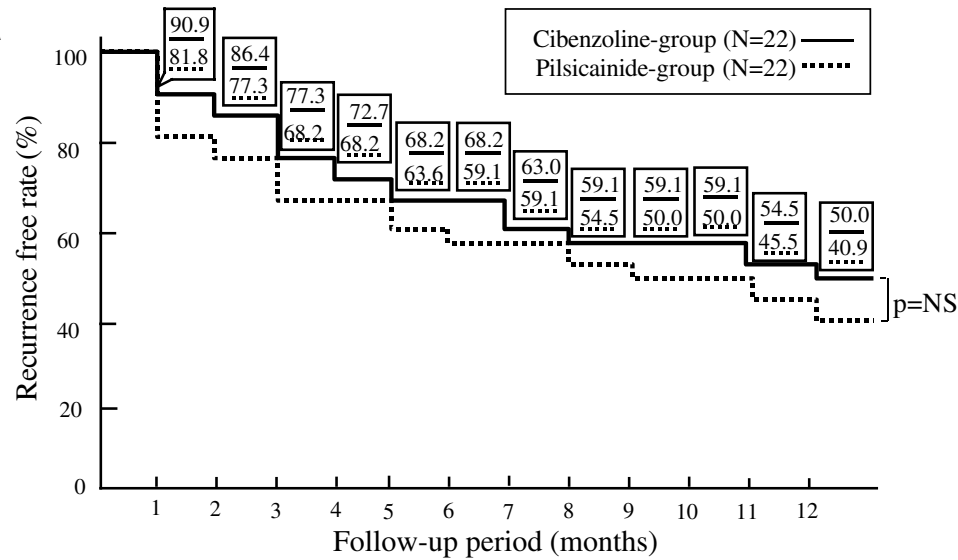

B

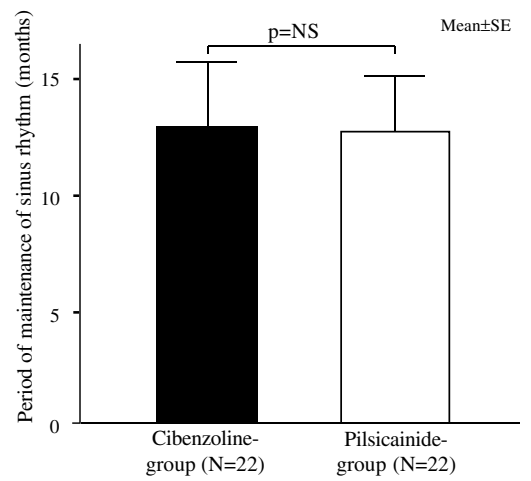

Fig 1. (A) Actuarial event-free rate of atrial fibrillation (AF) after oral pilsicainide and cibenzoline treatment in patients with AF lasting $<48 \mathrm{~h}$ after onset. (B) Duration of maintenance of sinus rhythm after oral pilsicainide and cibenzoline treatment in patients with $\mathrm{AF}$ lasting $<48 \mathrm{~h}$ after onset. Continuous value are mean $\pm \mathrm{SE}$.

A

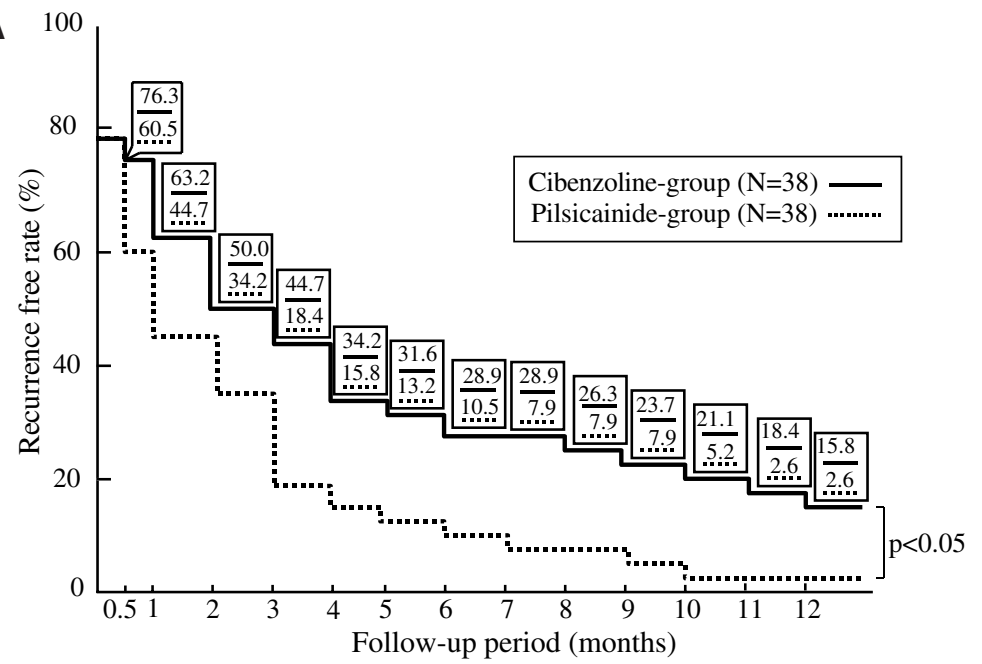

B

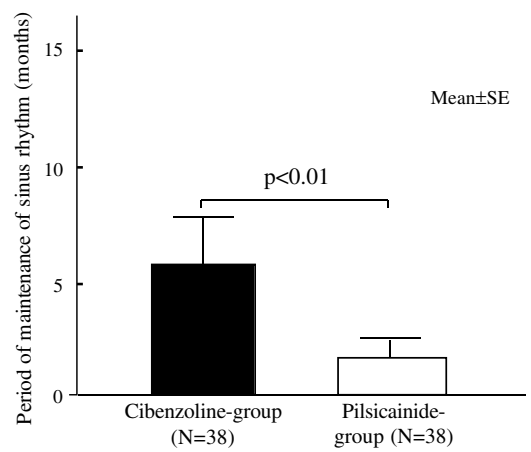

Fig 2. (A) Actuarial event-free rate of atrial fibrillation (AF) after oral pilsicainide and cibenzoline treatment in patients with AF lasting $\geq 48 \mathrm{~h}$ after onset. (B) Duration of maintenance of sinus rhythm after oral pilsicainide and cibenzoline treatment in patients with $\mathrm{AF}$ lasting $\geq 48 \mathrm{~h}$ after onset. Continuous value are mean $\pm \mathrm{SE}$.

density lesion greater than $3 \mathrm{~mm}$ on $\mathrm{CT}$ scanning of the head $!^{10}$ In the pulmonary function test, we regarded FEV 1.0 $\leq 70 \%$ as the diagnostic criterion for chronic obstructive pulmonary disease.

All data are shown as mean \pm standard deviation. The clinical profiles of the patients in Groups I and II were compared by one-way ANOVA for continuous variables and by the chi-square test for categorical ones. Survival curves were estimated by the Kaplan-Meier method and compared by the log-rank test. A p-value $<0.05$ was considered as a significant difference.

\section{Results}

The patients were divided into 2 groups according to the duration of AF as follows: Group I consisted of 22 patients who had AF lasting $<48 \mathrm{~h}$, ranging from 2 to $46 \mathrm{~h}$ (mean, $14 \pm 11 \mathrm{~h}$ ) and Group II consisted of 38 patients whose AF lasted for $\geq 48 \mathrm{~h}$, ranging from 52 to $864 \mathrm{~h}$ (mean, $184 \pm$ $235 \mathrm{~h}$ ). For the first-line agent, 29 patients received Pil and the remaining 31 patients received Cib.

\section{Comparison of the Clinical Profiles of Groups I and II (Table 1)}

There was no difference between the 2 groups in the age, gender, bodyweight, percentages of coronary risk factors and alcohol habits, distributions of underlying heart and pulmonary diseases, period of suffering AF, LV end-diastolic dimension or LVEF determined by echocardiography, plasma concentration of ANP at SR, or the time of occurrence. The left atrial dimension was significantly greater in Group II than in Group I ( $p<0.01,37 \pm 6 \mathrm{~mm}$ vs $32 \pm 6 \mathrm{~mm}$, respectively).

\section{Actuarial Recurrence-Free Rates and Period of Maintenance of SR in Group I Patients Treated With Pil or Cib}

Actuarial recurrence-free rates at 1, 3, 6, 9 and 12 months were $81.8 \%, 68.2 \%, 59.1 \%, 50.0 \%$ and $40.9 \%$ in patients treated with Pil, and $90.9 \%, 77.3 \%, 68.2 \%, 59.1 \%$ and $50.0 \%$, respectively, in those treated with Cib. There was no significant difference between the 2 groups during the follow-up period (Fig 1A). The mean period of maintenance 
of SR was $12.3 \pm 2.9$ months in patients treated with Pil, and $12.9 \pm 2.5$ months in those treated with Cib. There was also no significant difference between the 2 groups (Fig 1B).

\section{Actuarial Recurrence-Free Rates and Period of Maintenance of SR in Group II Patients Treated With Pil or Cib}

Actuarial recurrence-free rates at 1, 3, 6, 9 and 12 months were $44.7 \%, 18.4 \%, 10.5 \%, 7.9 \%$ and $2.6 \%$ in patients treated with Pil, and 63.2\%, 44.7\%, 28.9\%, $23.7 \%$ and $18.4 \%$, respectively, in those treated with Cib. Actuarial recurrence free rates at 12 months were significantly higher in patients treated with Cib than in those treated with Pil ( $\mathrm{p}<0.05$, Fig $2 \mathrm{~A}$ ). The mean period of maintenance of SR was $1.6 \pm 0.5$ months in patients treated with Pil, and $5.9 \pm 1.7$ months in those treated with Cib. The mean period of maintenance of SR was significantly higher in patients treated with $\mathrm{Cib}$ than in those treated with Pil $(\mathrm{p}<0.01$, Fig 2B).

\section{Results of Pharmacological/Electrical Cardioversion in Patients With PAF}

Pharmacological cardioversion was performed first for 22 cases in Group I and 8 cases in Group II (30/60 subjects), with a total success rate of $30 \%$ ( 8 of 22 cases in Group I (36\%), 1 of 8 cases in Group II (13\%)). No significant differences were noted between the groups $(\mathrm{p}=\mathrm{NS})$. Electrical cardioversion was performed for 14 cases in Group I and 37 cases in Group II in whom AF recurred during the administration of the first-line agent and had to be changed, a total of 51 cases, and successful cardioversion was achieved in all cases. In addition, conversion to permanent $\mathrm{AF}$ occurred in 10 of 60 cases $(15 \%)$ despite aggressive antiarrhythmic drug therapy.

\section{Discussion}

The up- or down-regulation of various ion channels occurs gradually in atrial muscle after prolonged rapid atrial pacing in experimental animal models. It is considered that these changes in atrial muscle are reversible if rapid atrial pacing only lasts several weeks or several months. If the atrial tachycardia lasts for several years or more, however, the changes become irreversible because myocardial fibrosis and degeneration occur in the atrial muscle! ${ }^{11}$ In experimental reports from animal models in which tachycardia lasted several hours to several months, there was down-regulation of the L-type calcium current $(\mathrm{IcaL})^{12,13}$ associated with excessive intracellular calcium loading, and down-regulation in the ultrarapid delayed rectifier potassium current (Ikur) ${ }^{14}$ transient outward potassium current (Ito),$^{13}$ sodium current ( $\left.\mathrm{INa}_{\mathrm{Na}}\right)^{15}$ and slow-type delayed rectifier potassium current (Iks) ${ }^{16}$ as an up-regulation of ion channels. In human atrial muscle that has been converted to permanent $\mathrm{AF}$, down-regulation of ion channels such as the L-type calcium current (IcaL) ${ }^{17}$ and transient outward potassium current (Ito) ${ }_{18}^{18}$ and up-regulation of the inward potassium current ( $\mathrm{Ikl})$ and acetylcholine-activated potassium current (IKach) ${ }^{17}$ have been reported, whereas neither the ultrarapid delayed rectifier potassium current $\left(\mathrm{Ikur}^{18}\right.$ nor rapid delayed rectifier potassium current $\left(\mathrm{Ikr}^{19}{ }^{19}\right.$ showed any changes. Those changes in the ion channels result in a shortened effective refractory period of atrial muscle and shortened excitable wave lengths according to the reduction of conduction velocity. Eventually, the arrhythmogenic substrate in which AF can be easily induced and prolonged is developed 19

In the present study, we divided patients with PAF into 2 groups according to the duration of AF: Group I consisted of patients in whom AF lasted for $<48 \mathrm{~h}$ and Group II consisted of those in whom AF lasted for $\geq 48 \mathrm{~h}$. The AHA guideline recommends that patients in whom $\mathrm{AF}$ lasts $\geq 48 \mathrm{~h}$ should be converted to SR by pharmacological and/or electrical cardioversion after adequate anticoagulant therapy, for 3 weeks before cardioversion and for 4 weeks afterward? All of the present patients in whom AF lasted $\geq 48 \mathrm{~h}$ underwent anticoagulant therapy before cardioversion, although eventually the strategy for restoring SR was determined by whether the duration of $\mathrm{AF}$ was $\geq 48 \mathrm{~h}$ or not. Accordingly, the atrial muscle in patients with AF lasting $\geq 48 \mathrm{~h}$ was more likely to have been influenced by up- or down-regulation of various ion channels caused by prolong tachycardia for the following reasons: cardioversion was performed after AF had lasted 10 or more days from the episode of PAF, and patients in the present study with spontaneous AF tend to have inherently arrhythmogenic substrates.

The present study showed no significant differences in the recurrence free rate between the Pil and Cib groups of patients in whom AF lasted $<48 \mathrm{~h}$, whereas the recurrence free rate was significantly higher in the Cib group than in the Pil group of patients in whom AF lasted $\geq 48 \mathrm{~h}$ at 12 months. Generally, Pil is considered to have a pure sodiumchannel-blocking action on single cardiac muscle cells ${ }^{20}$ If down-regulation of the sodium current ( $\mathrm{INa}$ ) has been caused by the development of atrial remodeling of patients in whom AF lasted for $\geq 48 \mathrm{~h}$, the preferred pharmacological action in relation to the ion channel may not occur in those patients. On the other hand, Cib is considered to have a multichannel blocking action, which blocks potassium and calcium channels in addition to the sodium channel ${ }^{20}$ In relation to its potassium channel-blocking action, there have been reports that Cib blocks the rapid (Ikr) as well as the slow (Iks) delayed rectifier potassium currents, inward potassium current ( $\mathrm{Ikl}$ ) and acetylcholine-activated potassium current (IKach)21,22 Because those ion channels were up-regulated or unchanged by the development of atrial remodeling following prolonged tachycardia, the preferred pharmacological action is expected. In fact, the present study showed that the recurrence-free rate in the Cib group was significantly higher than in the Pil group of patients in whom AF lasted for $\geq 48 \mathrm{~h}$.

During a follow-up period of 12 months, we found that the recurrence-free rate of patients treated with Pil and Cib in whom $\mathrm{AF}$ lasted $<48 \mathrm{~h}$ was approximately $40-50 \%$, which is consistent with that reported previously?23,24 In contrast, the recurrence-free rate of those in whom AF lasted for $\geq 48 \mathrm{~h}$ was $3-18 \%$, which was lower than in the previous reports. Some reasons for this result are: those patients finally had repeated AF recurrence despite the use of approximately 4 different antiarrhythmic agents on average after this trial; most of those patients had been suffering from PAF for approximately 2 years from the initial episode $; 2570 \%$ of those patients consisted of the mixed type according to the time of the occurrence and the $\mathrm{AF}$ was refractory to antiarrhythmic agent therapy; ${ }^{6}$ less than $20 \%$ of those patients were receiving concomitant angiotensin-converting enzyme inhibitor 26 which is considered to enhance the prevention of AF recurrence. 


\section{Study Limitations}

The recurrence-free rate of patients treated with Pil and Cib was not compared with that of a placebo group, so the possibility of maintenance of SR even without any antiarrhythmic agents cannot be excluded. Some large clinical trials have demonstrated that the recurrence-free rate of patients treated with placebo was $7 \% 27$ at 1 month, and $8-24 \%{ }^{28,29}$ at 2 and 3 months. In Japan, the SMART study (Sinus rhythm Maintenance in Atrial Fibrillation Randomized Trial) showed that the recurrence-free rate in a placebo group was $21 \%$ at 6 months 30 Thus, there are differences in the recurrence-free rate in patients treated with placebo among the several clinical reports in which study patients with various clinical profiles were evaluated. All of the present patients, however, were symptomatic and needed antiarrhythmic agent therapy. A placebo effect was unlikely to have affected our results because the follow-up period was longer (at 12 months) than in the previous reports and the study patients consisted of those with recurrent and symptomatic PAF.

Page et al, reported that in patients with PAF, sustained asymptomatic $\mathrm{AF}$ occurs far more frequently than symptomatic $\mathrm{AF}^{31}$ In the present study, all patients were considered to have no $\mathrm{AF}$ recurrence based on the symptoms and ECG findings taken once or twice a month at the outpatient clinic. The possibility of the occurrence of asymptomatic AF episodes in these patients cannot be excluded completely. According to another study in patients with symptomatic AF using Cardiophone (a portable ECG system), however, $30-70 \%$ of symptoms such as palpitation turned out to be sinus tachycardia or atrial extrasystole without $\mathrm{PAF} 3{ }^{32}$ From those results, the duration of tachycardia might be subjectively evaluated as in previous reports 31,32 if the duration of tachycardia in patients for whom AF had been observed at initial consultation was defined as between the onset of similar AF symptoms and the initial consultation. There is currently a methodological limitation in evaluating the initial episode of AF recurrence accurately by means of the symptoms and ECG findings.

\section{Conclusion}

Prolonged tachycardia ( $\geq 48 \mathrm{~h}$ ) in patients with PAF seems to cause electrical remodeling. Cib, a multichannel blocker, appears to be more effective in preventing the recurrence of PAF in electrically remodeled atria than Pil, a pure sodium-channel blocker. In addition, early cardioversion increases the subsequent long-term preventive effect of antiarrhythmic agent in patients with PAF.

\section{References}

1. Atrial Fibrillation Investigators. Risk factors for stroke and efficacy of antithrombotic therapy in atrial fibrillation: Analysis of pooled data from five randomized controlled trials. Arch Intern Med 1994; 154: $1449-1457$

2. Benjamin EJ, Wolf PA, D'Agostino RB. Impact of atrial fibrillation on the risk of death: The Framingham heart study. Circulation 1988; 98: $946-952$

3. Komatsu T, Nakamura S, Suzuki O, Horiuchi D, Yomogida K, Okumura K. Long-term prognosis of patients with paroxysmal atrial fibrillation depends on their response to antiarrhythmic therapy. Circ J 2004; 68: 729-733.

4. Kato T, Yamashita T, Sagara K, Iinuma H, Fu LT. Progressive nature of paroxysmal atrial fibrillation: Observations from a 14-year follow-up study. Circ J 2004; 68: 568-572.

5. Wijffels MCEF, Kirchhof CJHJ, Dorlald R, Allessie MA. Atrial fibrillation begets atrial fibrillation: A study in awake chronically instrumented goats. Circulation 1995; 92: 1954-1968.

6. Komatsu T, Nakamura S, Kimura M, Owada S, Saito E, Kobayashi $\mathrm{T}$, et al. Efficacy of cibenzoline in the termination and long-term prevention of paroxysmal atrial fibrillation: Analysis based on the tome of onset. J Cardiol 2001; 37: 75-82 (in Japanese with English abstract).

7. Prystowsky EN, Benson DW, Fuster V, Hart RG, Kay GN, Myerburg RJ, et al. Management of patients with atrial fibrillation. Circulation 1996; 93: $1262-1276$.

8. Manning WJ, Silverman DI, Keighley CS, Oettgen P, Douglas PS. Transesophageal echocardiography facilitated early cardioversion from atrial fibrillation using short-term anticoagulation: Final results of a prospective 4.5-year study. J Am Coll Cardiol 1995; 25: 13541361

9. World Health Organization. Arterial hypertension: WHO Technical Report Series, No. 628, 1978.

10. Koretune Y. COOPAT (Cooperative Osaka Platelet Antiaggregation Trial) Study. Ther Res 1996; 17: 33-37 (in Japanese).

11. Allessie MA. Atrial electrophysiologic remodeling. J Cardiovasc Electrophysiol 1998; 9: 1378-1393.

12. Geotte A, Honeycutt C, Langberg JJ. Electrical remodeling in atrial fibrillation: Time course and mechanisms. Circulation 1996; 94: $2968-2974$

13. Yue L, Feng J, Gaspo R, Li GR, Wang Z, Nattel S. Ionic remodeling underlying action potential changes in a canine model of atrial fibrillation. Circ Res 1997; 81: $512-525$.

14. Yamashita T, Murakawa Y, Hayami N, Fukui E, Kasaoka Y, Inoue $\mathrm{M}$, et al. Short-term effects of rapid pacing on the mRNA levels of voltage-dependent $\mathrm{K}^{+}$channels in the rat atrium: Electrical remodeling in paroxysmal atrial tachycardia. Circulation 2000; 101: $2007-$ 2014.

15. Gaspo R, Bosch RF, Bou-Abboud E, Nattel S. Tachycardia-induced changes in $\mathrm{Na}^{+}$current in chronic dog model of atrial fibrillation. Circ Res 1997; 81: 1045-1052.

16. Daoud EG, Knight BP, Weiss R, Bahu M, Paladino W, Goyal R, et al. Effect of verapamil and procainamide on atrial fibrillationinduced electrical remodeling in humans. Circulation 1997; 96: $1542-1550$

17. Bosch RF, Zeng X, Grammer JB, Popovic K, Mewis C, Kuhlkamp $\mathrm{V}$. Ionic mechanisms of electrical remodeling in human atrial fibrillation. Cardiovasc Res 1999; 44: 121-131.

18. Grammer JB, Bosch RF, Kuhlkamp V, Seipel L. Molecular remodeling of Kv4.3 potassium channels in human atrial fibrillation. $J$ Cardiovasc Electrophysiol 2000; 11: 626-633.

19. Nattel S, Li D. Ionic remodeling in the heart: Pathophysiological significance and new therapeutic opportunities for atrial fibrillation. Circ Res 2000; 87: 440-447.

20. Task Force of the Working Group on Arrhythmias of the European Society of Cardiology. The Sicilian gambit: A new approach to the classification of antiarrhythmic drugs based on their action on arrhythmogenic mechanisms. Circulation 1991; 84: 1831-1851.

21. Sato T, Wu B, Kiyosue T, Arita M. Effects of cibenzoline, a new class Ia anti-arrhythmic drug, on various membrane ionic currents and action potentials of guinea-pig ventricular cells. Naunyn Schmiedeberg's Arch Pharmacol 1994; 350: 167-173.

22. Wang DW, Kiyosue T, Sato T, Arita M. Comparison of the effects of class I antiarrhythmic drugs, cibenzoline, mexiletine and flecainide, on the delayed rectifier $\mathrm{K}^{+}$current of guinea-pig ventricular myocytes. J Mol Cell Cardiol 1996; 28: 893-903.

23. Ganz LI, Antman EM. Antiarrhythmic drug therapy in the management of atrial fibrillation. J Cardiovasc Electrophysiol 1997; 8: $1175-1189$.

24. Komatsu T, Nakamura S, Saito E, Kobayashi T, Kumagai K, Okumura K. Long-term preventive effects of pilsicainide, flecainide and bepridil on the recurrence of atrial fibrillation refractory to Ia and Ib antiarrhythmic agents. Shinzo 2000; 32: 699-705 (in Japanese).

25. Komatsu T, Nakamura S, Saito E, Kobayashi T, Kumagai K, Okumura K. Long-term efficacy of antiarrhythmic drugs in the prevention of paroxysmal atrial fibrillation: Significance of suffering period. Jpn J Electrocardiol 2000; 20: 27-32 (in Japanese).

26. Madrid AH, Bueno MG, Rebollo J MG, Marin I, Pena G, Bernal E, et al. Use of irbesartan to maintain sinus rhythm in patients with long-lasting persistent atrial fibrillation: A prospective and randomized study. Circulation 2002; 106: 331-336.

27. Pritchett ELC, Da Torre SD, Platt ML, McCarville SE, Hougham AJ, for the Flecainide Supraventricular Tachycardia Study Group. Flecainide acetate treatment of paroxysmal atrial fibrillation: Doseresponse studies. J Am Coll Cardiol 1991; 17: 297-303.

28. Anderson JL, Gilbert EM, Alpert BL, Henthorn RW, Waldo AL, Bhandari AK, and the Flecainide Supraventricular Tachicardia Study 
Group. Prevention of symptomatic recurrences of paroxysmal atrial fibrillation in patients initially tolerating antiarrhythmic therapy: A multicenter double-blind, crossover study of flecainide and placebo with transtelephonic monitoring. Circulation 1989; 80: 1557-1570.

29. UK Propafenone PSVT Study Group. A randomized, placebo-controlled trial of propafenone in the prophylaxis of paroxysmal supraventricular tachycardia and paroxysmal atrial fibrillation. Circulation 1995; 92: 2550-2557.

30. Atarashi H, Inoue H, Sugi K, Fukunami M, Origasa H, Hamada C. A randomized placebo controlled double-blind trial of aprindine, digoxin for the maintenance of sinus rhythm in patients with atrial fibrillation (Abstract). Jpn Circ J 2001; 65(Suppl): 193.

31. Page RL, Wilkinson WE, Clair WK, Mccarthy EA, Pritchett EL. Asymptomatic arrhythmias in patients with symptomatic paroxysmal atrial fibrillation and paroxysmal supraventricular tachycardia. Circulation 1994; 89: 224-227.

32. Fukuda Y, Akaishi M, Noma S, Mitamura H, Ogawa S. Asymptomatic recurrence of atrial fibrillation: Cardiophone-guided management (Abstract). Circ J 2003; 67(Suppl): 310. 